\title{
Apoptosis and autophagy have opposite roles on imatinib-induced K562 leukemia cell senescence
}

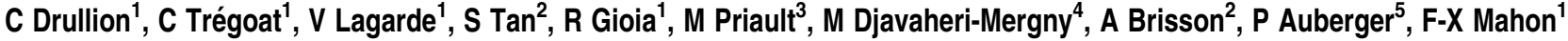 \\ and J-M Pasquet ${ }^{*, 1}$
}

Imatinib, the anti-Abl tyrosine kinase inhibitor used as first-line therapy in chronic myeloid leukemia (CML), eliminates CML cells mainly by apoptosis and induces autophagy. Analysis of imatinib-treated K562 cells reveals a cell population with cell cycle arrest, p27 increase and senescence-associated beta galactosidase (SA- $\beta$-Gal) staining. Preventing apoptosis by caspase inhibition decreases annexin V-positive cells, caspase-3 cleavage and increases the SA- $\beta$-Gal-positive cell population. In addition, a concomitant increase of the cell cycle inhibitors p21 and p27 is detected emphasizing the senescent phenotype. Inhibition of apoptosis by targeting Bim expression or overexpression of Bcl2 potentiates senescence. The inhibition of autophagy by silencing the expression of the proteins ATG7 or Beclin-1 prevents the increase of SA- $\beta$-Gal staining in response to imatinib plus Z-Vad. In contrast, in apoptotic-deficient cells (Bim expression or overexpression of Bcl2), the inhibition of autophagy did not significantly modify the SA- $\beta$-Gal-positive cell population. Surprisingly, targeting autophagy by inhibiting ATG5 is accompanied by a strong SA- $\beta$-Gal staining, suggesting a specific inhibitory role on senescence. These results demonstrate that in addition to apoptosis and autophagy, imatinib induced senescence in K562 CML cells. Moreover, apoptosis is limiting the senescent response to imatinib, whereas autophagy seems to have an opposite role.

Cell Death and Disease (2012) 3, e373; doi:10.1038/cddis.2012.111; published online 16 August 2012

Subject Category: Cancer

Chronic myeloid leukemia (CML) is a clonal proliferation malignancy characterized by a $\mathrm{t}(9 ; 22)(\mathrm{q} 34 ; \mathrm{q} 11)$ reciprocal translocation leading to the Philadelphia chromosome $\left(\mathrm{Ph}^{+}\right)$ with a fusion gene $B C R-A B L$, the molecular hallmark of $\mathrm{CML}$ and $\mathrm{Ph}^{+}$acute lymphoblastic leukemia. ${ }^{1}$ Targeting the tyrosine kinase (TK) activity of Bcr-Abl has been an attractive therapeutic strategy in CML with the development of new drugs such as tyrosine kinase inhibitors (TKIs). Imatinib mesylate (previously known as Gleevec or STI571) is a Bcr-Abl TKI that competes with the ATP-binding site of Bcr$\mathrm{Abl}$ and stabilizes the protein in its inactive conformation, thereby inhibiting its TK activity. ${ }^{2} \mathrm{Bcr}-\mathrm{Abl}$ is one of the main targets of the TKI imatinib mesylate $\left(\right.$ Gleevec $^{\mathrm{R}}$ or Glivec $^{\mathrm{R}}$, previously STI571), which also inhibits c-Kit (the receptor for SCF), the PDGF receptor, Abl and the Abl-related gene. ${ }^{3}$ The resulting inhibition of the kinase activity leads to apoptosis of leukemic cells sparing normal hematopoiesis. ${ }^{2}$ Several studies suggest that TKIs induce caspase-independent cell death (CICD) among which necrosis or lysosomal permeabilization but also surviving mechanisms like autophagy. Some of these different deaths or survival pathways have a role in the response to imatinib. ${ }^{4,5}$ However, other cell deaths still remain to be studied. Although the efficient therapeutic use of TKI-targeting Abl in CML disease has been associated with the apoptosis of the Philadelphia-positive cells, CICD have been reported at least in vitro and frequently unmasked by caspase inhibition. ${ }^{6,7}$

Apoptosis is by far the best characterized type of cell death and classified as programmed cell death I. It is defined by morphological features (rounding up of the cell, reduction of cellular and nuclear volume, nuclear fragmentation, plasma membrane blebbing and phosphatidylserine exposure, loss of mitochondrial membrane potential) and caspase activation. For a long time, apoptosis was the only death reported in response to imatinib associated with a controlled mechanism. However, recent studies suggest that necrosis, considered for a long time as an accidental kind of death, would result from accurate mechanisms. ${ }^{8}$ Interestingly, there are other ways to die such as when autophagy is overbooked. ${ }^{9}$ Macroautophagy (refered as autophagy) has first been demonstrated to be a self-proteolysis system involved in the rescue of the cell to maintain homeostasis. ${ }^{10}$ It is a well-organized catabolic mechanism allowing recycling of macromolecules triggered by stress conditions. ${ }^{11}$ Autophagy is characterized by double

\footnotetext{
${ }^{1}$ Laboratoire hématopoièse leucémique et cibles thérapeutiques, INSERM U1035, Université Bordeaux Ségalen, 146 rue Léo Saignat Bat TP $4^{\mathrm{e}}$ étage, 33076 Bordeaux, cedex, France; ${ }^{2}$ UMR-5248-CBMN, Université de Bordeaux, Bâtiment B8-Avenue des Facultés, 33405 Talence, France; ${ }^{3}$ UMR CNRS 5095, I.B.G.C, 1 rue Camille Saint Saens, Université de Bordeaux, 33077 Bordeaux, France; ${ }^{4}$ INSERM U916 VINCO, Institut Bergonié, 33076 Bordeaux, France and ${ }^{5}$ INSERM U1065, Team 2, C3M, 151 route de ginestière, 06204 Nice, France

*Corresponding author: J-M Pasquet, Laboratoire hématopoièse leucémique et cibles thérapeutiques, INSERM U1035, Université Bordeaux Ségalen, 146 rue Léo Saignat Bat TP $4^{\mathrm{e}}$ étage, 33076 Bordeaux cedex, France. Tel +33 05575745 47; Fax +33 05569388 83; E-mail: jean-max.pasquet@u-bordeaux2.fr Keywords: chronic myeloid leukemia; autophagy; senescence; BCR-ABL; tyrosine kinase inhibitors

Abbreviations: ATF5, activating transcription factor 5; ATG, autophagy-related genes; Bcl-2, B-cell CLL/lymphoma 2; Bim, Bcl-2 interacting mediator; CML, Chronic myeloid leukemia; shRNA, short hairpin RNA; TAF6, Transcription initiation factor TFIID subunit 6; TEM, Transmission Electron Microscopy; TK, tyrosine kinase; TKI, tyrosine kinase inhibitor; Z-Vad-fmk, Benzyloxycarbonyl-Val-Ala-Asp (OMe) fluoromethylketone

Received 02.12.11; revised 18.6.12; accepted 18.6.12; Edited by A Stephanou
} 
membrane vesicle formation called autophagosome, a massive vacuolization and can become a death pathway in not yet well-defined conditions. ${ }^{9,12}$ Even CML cells can be eliminated through a resveratrol-mediated autophagic cell death. ${ }^{13}$ There is now mounting evidence that autophagy and apoptosis share several common regulatory elements. ${ }^{14,15}$ In contrast, senescence has been associated with age and telomere shortening or stress conditions. ${ }^{16,17}$ Senescence is characterized by molecular and morphological cell changes such as an irreversible cell cycle arrest, an increase of cell granulation and size and an increase of lysosome. ${ }^{18,19}$ Senescent cells also share biochemical modifications, such as an increase of senescence-associated $\beta$-galactosidase activity (SA- $\beta$-gal), overexpression of cell cycle inhibitors (p21, p53, p16), specific wnt protein expression and a strong resistance to apoptosis. ${ }^{20}$ They have still an active metabolism and lots of attention is now on the secreted proteins during senescence. Indeed, senescence could participate in the quality of cell response to therapeutic treatment but also to eliminate oncogenic-transformed cells. ${ }^{17,21}$

Imatinib has recently been described to be involved in a senescent response of thyroid cancer cells or a quiescent phase of gastrointestinal stromal tumor cells. ${ }^{22,23}$ However, these responses have yet to be determined in imatinib-treated CML cells. To answer if imatinib triggers senescence in CML cells, we studied how $\mathrm{K} 562 \mathrm{CML}$ cells died in response to imatinib and the interplay between apoptosis, autophagy and senescence.

\section{Results}

Imatinib induced apoptosis, autophagy and a senescentlike phenotype in K562 cells. In an attempt to characterize if imatinib is inducing other cell death than apoptosis, we detect apoptosis, autophagy and senescence in K562 cells. $\mathrm{K} 562$ cells were first incubated with $1 \mu \mathrm{M}$ of imatinib for 24 , 48 and $72 \mathrm{~h}$. Then, annexin $\mathrm{V}$ binding and SA- $\beta$-Gal were measured. In response to imatinib, apoptosis was detected at $24 \mathrm{~h}$ and still increased at $72 \mathrm{~h}$ (Supplementary Figure $1 \mathrm{~A}$ ). $\mathrm{SA}-\beta$-Gal was maximal at $48 \mathrm{~h}$ and led us to choose $48 \mathrm{~h}$ of incubation to detect apoptosis, autophagy and senescence. The apoptotic response of $\mathrm{K} 562$ cells upon $48 \mathrm{~h}$ imatinib treatment was also confirmed by the detection of the cleaved caspase-3 fragment (Figure 1a). A mean of $35 \%$ of annexin $\mathrm{V}$-labeled $\mathrm{K} 562$ cells were detected in response to imatinib on eight independent experiments. To detect autophagy, the ATG8-related human protein LC3 (the microtubule-associated protein 1 light chain 3) was detected by western blot. K562 cells were treated with $20 \mathrm{nM}$ of Bafilomycin $\mathrm{A} 12 \mathrm{~h}$ before the end of the 48-h imatinib incubation to block the autophagic flux through the inhibition of the autophagolysosome formation. Bafilomycin incubation leads to the accumulation of the lipidated form of LC3 (LC3BII) allowing easier detection of the autophagic marker (Supplementary Figures $2 \mathrm{~A}$ and $\mathrm{B}$ ). Upon 48-h imatinib incubation, LC3BII accumulates in K562 cells showing an autophagic response (Figure 1b). This was also confirmed by the detection of mcherry-tagged LC3 proteins (Supplementary Figure 2C). Senescence was observed by the detection of SA- $\beta$-Galpositive cells, the increase of cell size and the expression of the cell cycle inhibitors p21 and p27 (Figure 1c and Supplementary Figure 1e). Imatinib induced an increase of SA- $\beta$-Gal-positive cells ( $38 \%$ of SA- $\beta$-Gal-positive cells were detected in response to imatinib versus $14 \%$ in untreated cells, Figure 1c). A decrease of the cell cycle inhibitors p21 (3-fold) and an increase of p27 (4.6-fold) were detected in imatinib-treated cells upon $48 \mathrm{~h}$ in comparison to untreated cells (Figure 1d).

Inhibition of imatinib-induced apoptosis potentiates cell cycle inhibitor expression and SA- $\beta$-Gal-positive cell population. As apoptosis, autophagy and senescence are detected in K562 cells upon 48-h imatinib incubation, we would determine if regulations exist between these responses. Using the broad caspase inhibitor Z-Vad-fmk (Z-Vad), the annexin V-positive cell population was lesser than $8 \%$ in response to imatinib plus Z-Vad (Figure 1a). In addition, incubation of K562 cells with imatinib plus Z-Vad induced $70 \%$ of SA- $\beta$-Gal-positive cells (Figure 1c). This was paralleled by an increase of p21 (12-fold) and p27 (21-fold) expression, suggesting that apoptosis limits the senescent response may be through p21 and p27 downregulation (Figure 1d and Supplementary Figure 1D).

To test this hypothesis, we generate apoptosis-deficient K562 cells by inhibiting the expression of the proapoptotic protein Bim or by overexpressing the anti-apoptotic protein Bcl2 (Figure 2a). The detection of annexin V-positive cells in response to imatinib in the K562 shRNA Bim (KS sh Bim) and $\mathrm{K} 562 \mathrm{Bcl} 2$ (KS Bcl2) show no significant increase in comparison to untreated cells (Figure 2b), confirming that both Bim inhibition and $\mathrm{Bcl} 2$ overexpression inhibit imatinib-induced apoptosis. The SA- $\beta$-Gal-positive cells were increased in untreated $\mathrm{KS}$ sh Bim or KS Bcl2 cells and still increase upon 48-h imatinib incubation (Figure 2c).

Imatinib-induced senescence in $\mathrm{K} 562$ cells is linked to autophagy. Because autophagy is limiting the apoptotic response to imatinib, we investigate if it also regulates imatinib-induced senescence. ATG7-deficient K562 cells (KS shATG7) were generated using a short hairpin RNA (shRNA) anti-ATG7 by lentiviral infection of $\mathrm{K} 562$ cells as previously described $^{24}$ (Figure 3a). These cells show a moderate increase of the autophagic marker LC3B in response to imatinib confirming the inhibition of the autophagy process (compare Figure $3 a$ with Figure 1a and Supplementary Figures 2B and C). ATG7-deficient K562 cells treated with $1 \mu \mathrm{M}$ imatinib for $48 \mathrm{~h}$ have an increase of annexin $\mathrm{V}$ binding (Figure $3 b$ ). Imatinib induced a similar level of SA- $\beta$ Gal in KS shATG7 cells in comparison to K562 cells, suggesting that ATG7 inhibition did not abrogate imatinibinduced senescence, which is associated with a p21 decrease (5-fold) and a p27 increase (4-fold). In contrast, incubation with imatinib plus Z-Vad was not associated with an increase of SA- $\beta$-Gal-positive cells but there is still an increase of p21 (3.5-fold) and p27 (11-fold) expression (Figure 3c). Transmission electron microscopy (TEM) analysis of KS shATG7 cells treated with imatinib or imatinib plus Z-Vad show large vacuoles but no autophagosome (Supplementary Figure 3a). 
a

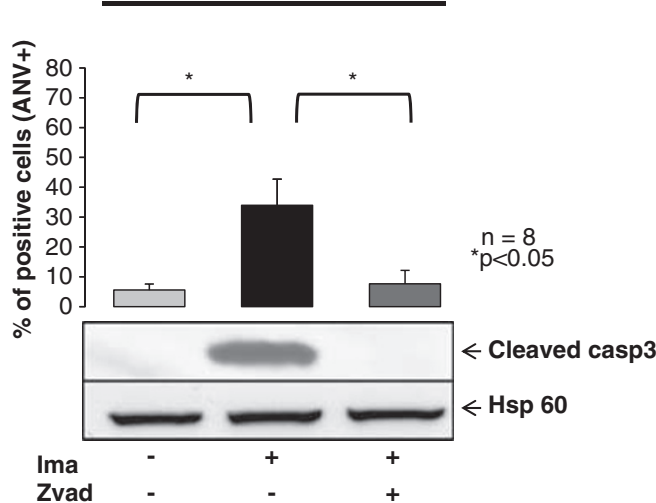

C
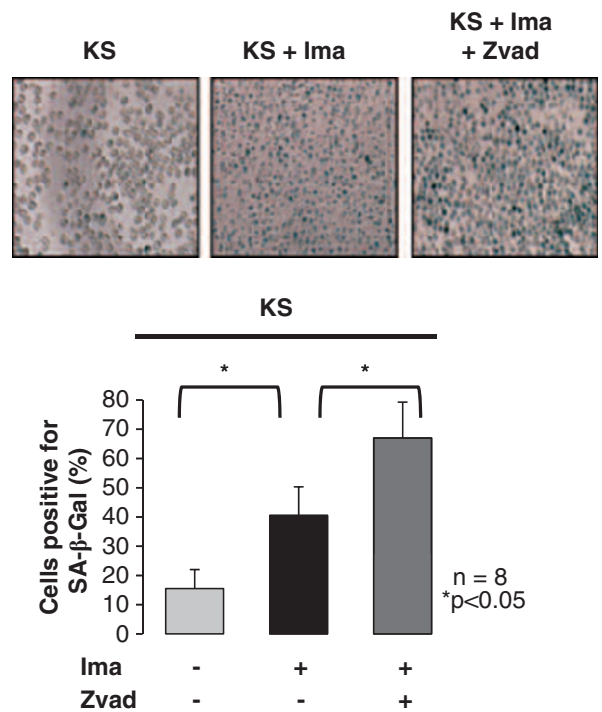

b

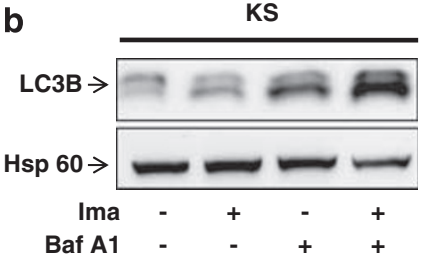

d

KS
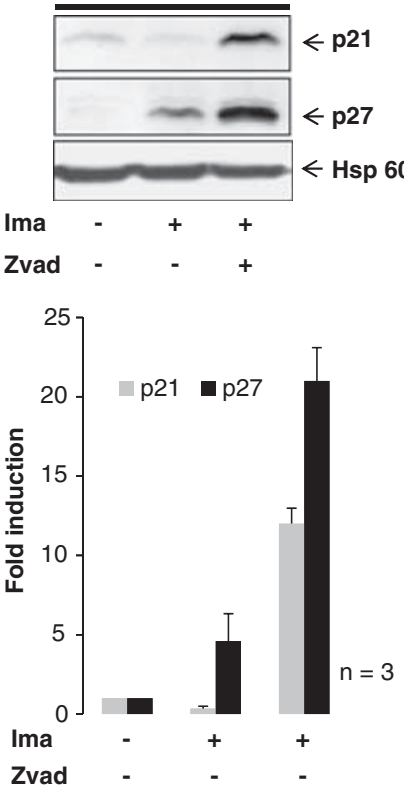

Figure 1 Imatinib-induced senescence of $\mathrm{K} 562$ cells is potentiated by caspase inhibition. K562 cells were grown in the presence of vehicle only, imatinib (Ima, $1 \mu \mathrm{M})$ or preincubated 30 min with Z-vad $(50 \mu \mathrm{M})$ and then Ima $(1 \mu \mathrm{M})$ for $48 \mathrm{~h}$. An aliquot was incubated for $10 \mathrm{~min}$ in the presence of annexin-V-FITC. Samples were analyzed by flow cytometry and labeled cells were quantified as described in Materials and Methods. Results from eight experiments are expressed as the percentage of annexin V-labeled cells (a). Samples treated as above were used for detection of the cleaved form of caspase 3 by western blot and Hsp60 (as loading control). LC3B proteins were detected by western blot and Hsp60 was used as loading control (b). K562 cells treated as above (10 5 cells) was washed in PBS, fixed in PFA (4\%) during 15 min and then incubated overnight in a 96 -well plate in the presence of X-Gal $(1 \mathrm{mg} / \mathrm{ml})$ at $37^{\circ} \mathrm{C}$ as described in Materials and Methods. The day after, the cells were washed once in PBS and SA- $\beta$-Gal activity was detected by a blue cell staining visualized under an inverted microscope. Pictures were acquired and analyzed using the NIS Nikon software. A representative result is shown in the top of the figure (c). SA- $\beta$-Gal-positive cells were quantified by counting $10^{2}$ cells on three separate fields for each condition. Results show the mean of eight independent experiments (c). The proteins p21, p27 and Hsp60 were detected and the latter was used as a loading control. Results are from one experiment representative of three. The level of expression of p21 and p27 were quantified by densitometry analysis using ImageJ and results were normalized to the untreated condition (d)

Imatinib-induced senescence in apoptotic and autophagicdeficient K562 cells. To confirm the limiting role of apoptosis on imatinib-induced senescence, we used tetracycline-inducible shRNA anti-caspase 3 and 9. Although induction of shRNA anti-caspase 3 and 9 decreased their targets, respectively, imatinib induced a decrease of p21 and an increase of p27, which is surprisingly still associated with apoptosis and SA- $\beta$-Gal (Supplementary Figure 4), suggesting that these caspases are not critical for K562 cells responses to imatinib.

To investigate the role of autophagy in imatinib-induced senescence, we used the Bim-deficient and Bcl2-overexpressing K562 cells to generate double knock-down Bim/ATG7 cells and Bcl2-overexpressing/ATG7-deficient cells (Figure 4a).
Incubation with imatinib for $48 \mathrm{~h}$ did not increase the number of annexin V-labeled cells confirming the inhibition of the apoptotic response previously observed (Figure $4 b$ ). To test the effect of the inhibition of both apoptosis and autophagy on imatinib-induced senescence, we incubate these cells with imatinib for $48 \mathrm{~h}$. Although the level of the SA- $\beta$-Gal-positive cells in untreated K562 Bim/ATG7- and KS Bcl2/sh ATG7deficient cells was elevated and similar to the single KS sh Bim or KS Bcl2 cells, imatinib still induced an increase of the SA- $\beta$ Gal-positive cells (Figure 4c). However, inhibition of both autophagy and apoptosis decreases the senescent response to imatinib similar to the imatinib plus Z-Vad-treated KS shATG7 cells (compare Figures $3 c$ and $4 c$ ). To confirm this result, inhibition of Beclin-1 and ATG5 was performed by 
a

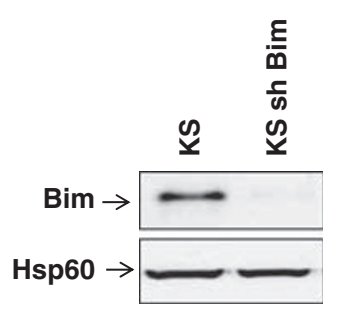

b

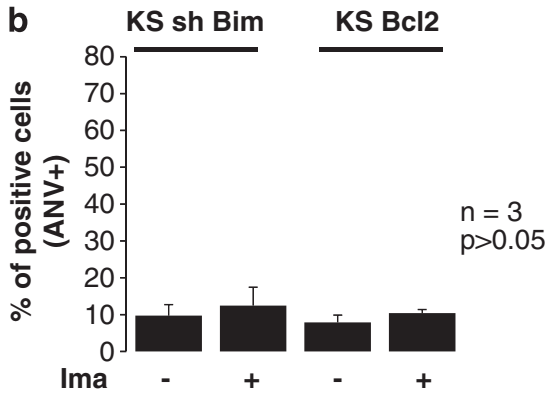

C

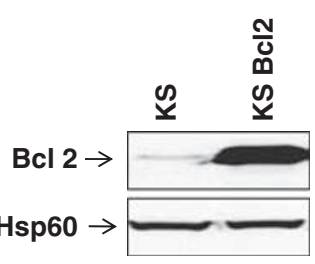


a
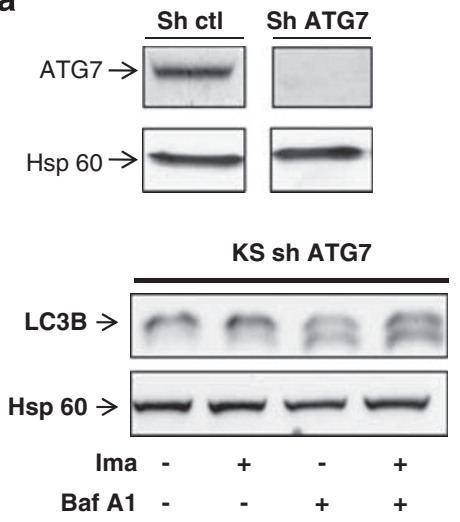

C
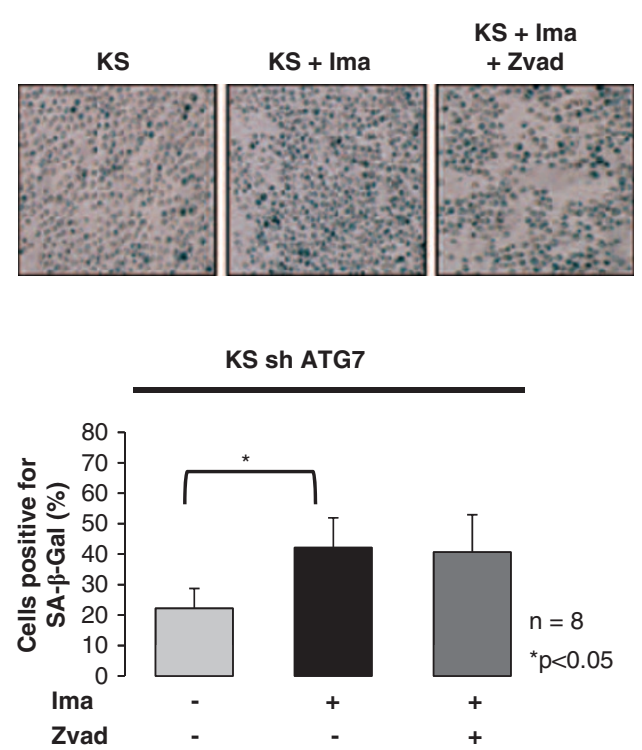

b

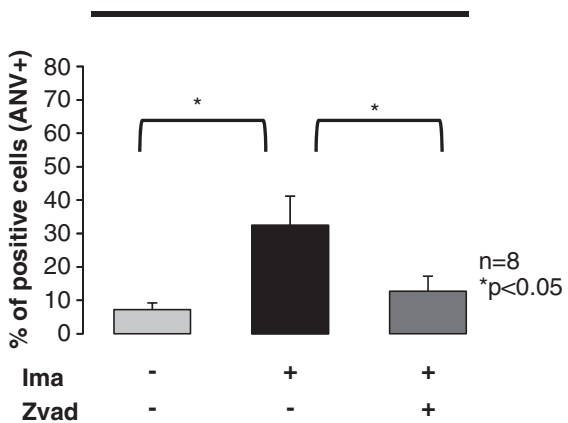

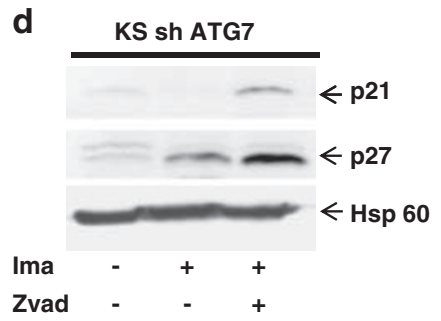

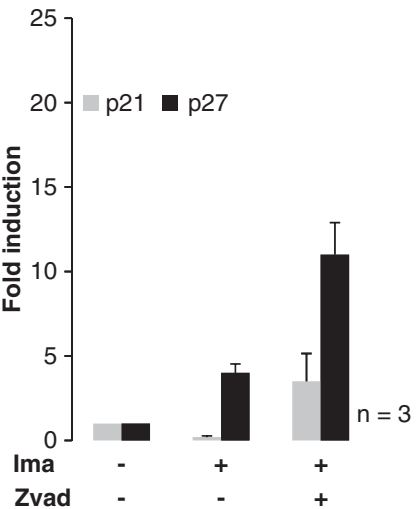

Figure 3 Autophagy-deficient cells have impaired potentiation of senescence. K562 cells were infected by lentivirus coding for a shRNA anti-ATG7 by incubation for $24 \mathrm{~h}$. Then, the cells were washed twice in PBS and grown for 6 days before sorting. Samples were analyzed for ATG7 expression by western blotting and inhibition of autophagy by detecting LC3B proteins by western blot (a). K562 shATG7 cells were incubated with vehicle only, imatinib (Ima, $1 \mu \mathrm{M})$ or incubated with Z-vad (50 $\mu \mathrm{M})$ and Ima (1 $\mu \mathrm{M})$ for $48 \mathrm{~h}$. Then, an aliquot was incubated for $10 \mathrm{~min}$ in the presence of annexin-V-FITC. Samples were analyzed by flow cytometry and labeled cells were analyzed as described in Materials and Methods. Results from eight experiments are expressed as the percentage of annexin V-labeled cells (b). K562 shATG7 cells treated as above (10 ${ }^{5}$ cells) was washed in PBS, fixed in PFA (4\%) during $15 \mathrm{~min}$ and then incubated overnight in a 96-well plate in the presence of X-Gal $(1 \mathrm{mg} / \mathrm{ml})$ at $37^{\circ} \mathrm{C}$ as described in Materials and Methods. The day after, the cells were washed once in PBS and SA- $\beta$-Gal activity was detected by a blue cell staining visualized under an inverted microscope. Pictures were acquired and analyzed using the NIS Nikon software. A representative result is shown in the top of the figure (c). SA- $\beta$-Gal-positive cells were quantified by counting $10^{2}$ cells on three separate fields for each condition. Results show the mean of eight independent experiments (c). The proteins p21, p27 and Hsp60 were detected and the latter was used as a loading control. Results are from one experiment representative of three. The level of expression of p21 and p27 was quantified by densitometry analysis using ImageJ and results were normalized to the untreated condition (d)

of $\mathrm{Bcl} 2$ blocks apoptosis and increases senescence in response to imatinib, emphasizing previous results. Moreover, these results confirmed that CICD occurred in imatinibtreated CML cells and increased when caspases or apoptosis are inhibited. ${ }^{6,7}$ Lavallard et al. ${ }^{7}$ report CICD in CML cells in response to imatinib. This has not been associated with senescence, although the response to imatinib was correlated with the inhibition of colony formation in clonogenic assay and even more when apoptosis is inhibited, suggesting a cell cycle arrest or cell death. Another CICD has been reported in response to imatinib when apoptosis was prevented by caspases inhibition. ${ }^{6}$ In regard to the necrosis-like cell death reported by Okada et al., ${ }^{6}$ we investigated the role of the serine protease Omi/HtrA2 in imatinib-induced senescence using the inhibitor ucf-101. At least in our hand, both the increase of p21 and p27 and the SA- $\beta$-Gal-positive cell population was not prevented or decreased by blocking Omi/ $\mathrm{HtrA2}$, suggesting that the release of this protease is not involved in the senescent response (Drullion, unpublished data). In addition, no significant propidium iodide (PI)-labeled 

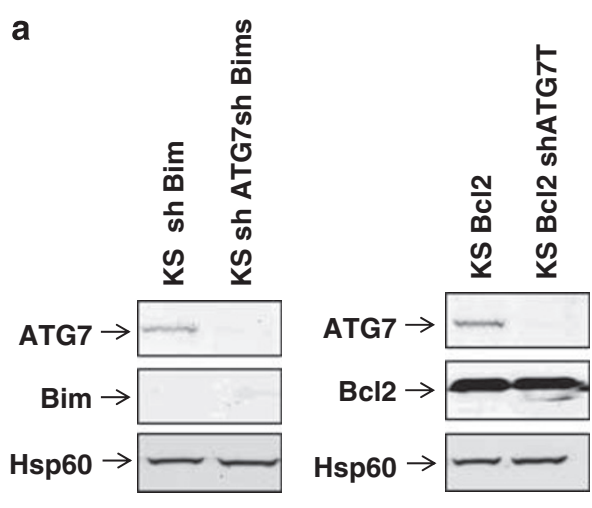

C b

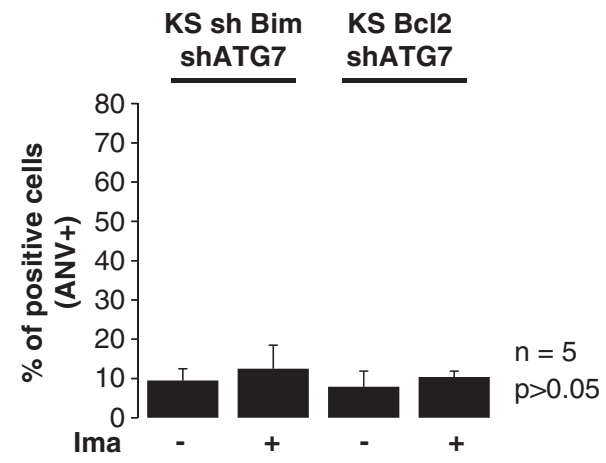

KS Bcl2 ShATG7

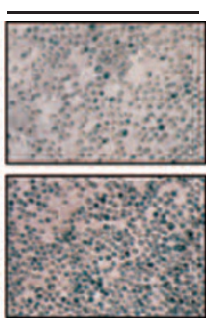

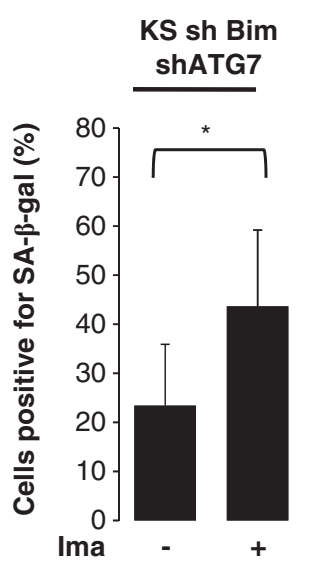

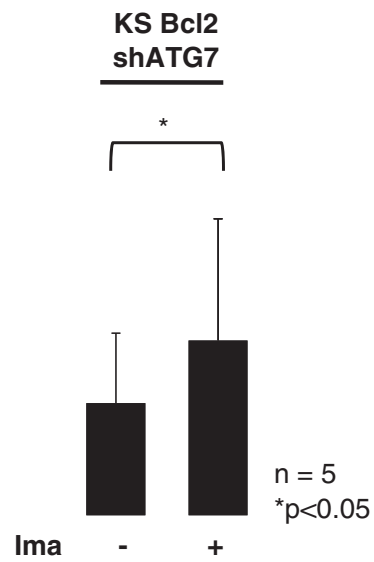

Figure 4 Inhibition of apoptosis and autophagy limits imatinib-induced K562 cell senescence. K562 sh Bim and K562 Bcl2 cells were infected by incubation for $24 \mathrm{~h}$ with lentivirus coding for a shRNA anti-ATG7. Then, the cells were washed twice in PBS and grown for 6 days before sorting as described in Materials and Methods. Samples were analyzed for Bim, Bcl2 and ATG7 expression by western blotting (a). K562 sh Bim/sh ATG7 and K562 Bcl2/sh ATG7 cells were incubated with vehicle only or imatinib (Ima, $1 \mu \mathrm{M}$ ) for $48 \mathrm{~h}$. Then, an aliquot was incubated for $10 \mathrm{~min}$ in the presence of annexin-V-APC. Samples were analyzed by flow cytometry and labeled cells were analyzed as described in Materials and Methods. Results from five experiments are expressed as the \% of annexin V-labeled cells (b). K562 sh Bim/sh ATG7 and K562 Bcl2/sh ATG7 cells were treated as above ( $10^{5}$ cells) and washed in PBS, fixed in PFA (4\%) during $15 \mathrm{~min}$ and then incubated overnight in a 96-well plate in the presence of X-Gal ( $1 \mathrm{mg} / \mathrm{ml}$ ) at $37^{\circ} \mathrm{C}$ as described in Materials and Methods. The day after, the cells were washed once in PBS and SA- $\beta$-Gal activity was detected by a blue cell staining visualized under an inverted microscope. Pictures were acquired and analyzed using the NIS Nikon software. A representative result is shown in the top of the figure (c). SA- $\beta$-Gal-positive cells were quantified by counting $10^{2}$ cells on three separate fields for each condition. Results show the mean of five independent experiments (c)

cells was detected upon 48-h imatinib incubation and this was not increased by inhibition of caspase. Only dual Pl/annexin $\mathrm{V}$-labeled cells were detected in our experiments at longer time. This may suggest that $\mathrm{K} 562$ cells are more competent to die through senescence than necrosis in response to imatinib; a response more convincing when apoptosis is blocked. Interestingly, it should be noted that another CML cell line, BV173, undergoes more PI labeling than K562 cells upon 48-h imatinib incubation. Indeed, only cells undergoing mitochondrial depolarization were PI labeled, suggesting again that PI labeling may reflect the late stage of the apoptosis.

One major result of this study is imatinib induced, in addition to apoptosis and autophagy, a senescence-like change in K562 cells. It was already reported that imatinib triggers senescence (detected by an increase of p21 expression) in radiation-treated thyroid cancer cells or induces quiescence in GIST cells. ${ }^{22,23}$ Furthermore, the senescent response observed was amplified by caspase or apoptosis inhibition. 
A similar result was reported in neuroblastoma cells treated by increasing concentration of doxorubicin without caspase activation. ${ }^{27}$ This is in accordance with the limiting role of apoptosis on senescence in a caspase-dependent way. This is also highlighted by the increase of p21 expression and SA- $\beta$-Gal-positive cells at a concentration of doxorubicin, which did not activate caspase 3 . At higher concentration of doxorubicin, leading to caspase-3 activation and p21 degradation, death switches to apoptosis. Conversely, p21 increase cannot be observed until caspases are inhibited emphasizing our result in $\mathrm{K} 562 \mathrm{CML}$ cells. However, we were not able to confirm these results using K562 cells deficient for caspases 3 or 9 . Although tetracycline-induced shRNA against caspase 3 or 9 decreased their expression and activation, they did not prevent imatinib-induced apoptosis and senescence. We also cannot rule out that Z-Vad has additional targets. For example, the cysteine-protease calpains have been involved in the proteolysis of specific substrates and may be inhibited to some extent by Z-Vad. Indeed, calpain activation has been associated with senescence in response to DNA damage. ${ }^{28}$ However, using E-64-d, a calpain and cathepsin inhibitor, or CA074-Me, a cathepsin B inhibitor, we were unable to prevent p21 decrease in response to imatinib. The cell cycle arrest and the senescent response detected in imatinib-treated K562 cells could be linked to some other caspase substrates, such as the retinoblastoma protein $(\mathrm{Rb})$ involved in E2F binding and proliferation or TAF6, a transcription factor involved in p21 expression even in the absence of $p 53 .^{29,30}$

Besides the induction of senescence by imatinib, we identified two levels of senescence. The first one occurred in addition to apoptosis in response to imatinib, whereas the last was unmasked when apoptosis is inhibited. This later seems to be dependent on autophagy, as it was significantly decreased in two autophagic-deficient K562 cell lines (KS sh ATG7 and sh-Bcn). Indeed, autophagy has been connected to senescence in physiopathology, but its role is still controversial. ${ }^{15,31-33}$ For example, mTor inhibition by resveratrol or rapamycin was reported to increase autophagy and suppress cellular senescence. ${ }^{34}$ In our condition, senescence in response to imatinib was neither increased nor modified by rapamycin, an inhibitor of $m$ Tor (results not shown). Inhibition of ATG5 expression in K562 cells was accompanied by a strong increase of SA- $\beta$-Gal, but not anymore by imatinib or imatinib plus Z-Vad incubation. Although shATG7, sh-Bcn and sh-ATG5 inhibit imatinib-induced autophagy in K562 cells, basal and induced SA- $\beta$-Gal were maximal in KS shATG5. We have not yet identified the molecular pathway explaining the discrepancy observed. In addition, the role of ATG5 in the senescent response is still controversial. Indeed, a similar increase of senescence has been reported in fibroblasts in response to ATG5 protein inhibition, whereas it inhibits both autophagy and senescence induced by $\mathrm{H}_{2} \mathrm{O}_{2}$ in the WI38 fibroblast cells through a p38 mitogen-activated protein kinase and p21 pathway. ${ }^{35,36}$ Because apoptosis is limiting autophagy, at least through the proteolysis of autophagy-regulating proteins, potentiating senescence upon inhibition of apoptosis may take place in an autophagydependent way. This may explain why Bim-deficient $\mathrm{K} 562$ cells (sh Bim) undergo high basal SA- $\beta$-Gal-positive cell population, although it is not significantly different from K562 sh Bim/sh ATG7. When apoptosis was blocked by overexpression of $\mathrm{Bcl} 2$, the $\mathrm{SA}-\beta$-Gal-positive cell population was similar. $^{37,38}$ A recent report describes that Bcr-Abl inhibits autophagy through an ATF5-mediated regulation of mTOR transcription. ${ }^{39}$ In this way, this may contribute to the absence of senescence in Bcr-Abl-expressing cells while such oncogene expression should normally induce an oncogeneinduced senescence response. Indeed, the inhibition of Bcr-Abl activity by imatinib blocks the BCR-ABL/PI3K/AKT/ FOXO4/ATF5/mTOR pathway and consequently may induce autophagy and senescence.

This study reports for the first time that imatinib is able to induce senescence in K562 CML cells and confirms interplay between the different death and survival pathways. Many questions have still to be answered concerning the molecular network interconnecting these responses. However, the possibility to induce senescence in cancer cells is very exciting as it is the first barrier against tumorigenesis.

\section{Materials and Methods}

Reagents. RPMI 1640 medium, fetal calf serum, phosphate-buffered saline (PBS), were from Invitrogen (Life Technologies SAS, Saint Aubin, France). Trypan blue and the antibody against LC3 were from Sigma (St. Quentin Fallavier, France). TKIs Imatinib and Nilotinib were kindly provided by Novartis Pharma (Basle, Switzerland). The broad caspase inhibitors Z-VAD-fmk were purchased from Peptanova (Sandhausen, Germany). Cyto-ID autophagy detection kit was from Enzo Life Sciences (Villeurbanne, France) and used in flow cytometry. The following antibodies: caspase 3 and 9, p21, p27 were from Cell Signalling (Danvers, MA, USA), and Hsp60 was from Santa Cruz (Bergheimer, Germany). Annexin-V-FITC and APC were from Beckman Coulter (Villepinte, France).

Cell lines. The human erythroleukemia Bcr-Abl-positive human cell line used in this study: K562 (KS) was from ATCC. Cells were maintained in RPMl 1640 medium supplemented with $10 \%$ fetal calf serum, $2 \mathrm{mM}$ L-glutamine, $100 \mathrm{U} / \mathrm{ml}$ penicillin and $0.1 \mathrm{mg} / \mathrm{ml}$ streptomycin at $37^{\circ} \mathrm{C}$ in a humidified atmosphere containing $5 \% \mathrm{CO}_{2}$. Aliquots were taken at $24 \mathrm{~h}$ intervals for assessment of cell viability by Trypan blue exclusion. K562 sh caspase 3 and sh caspase 9 were generated as previously described. ${ }^{40}$

Transmission electron microscopy (TEM). K562 cells were processed for ultramicrotomy according to standard procedures. Cell pellets were fixed for $2 \mathrm{~h}$ in a mixture of $2.5 \%$ glutaraldehyde and $4 \%$ paraformaldehyde in $0.2 \mathrm{M}$ cacodylate buffer ( $\mathrm{pH} 7.4$ ) and post-fixed for $1 \mathrm{~h}$ at $4{ }^{\circ} \mathrm{C}$ with $1 \%$ osmium tetroxide in the same buffer. The pellets were dehydrated with ethanol and embedded in Epon-Araldite. Thin sections were stained successively with $5 \%$ uranyl acetate and $1 \%$ lead citrate. TEM observation was performed with a FEI CM120 operated at $120 \mathrm{kV}$ (FEI, Eindhoven, The Netherlands). Images were recorded with a USC1000 slow scan CCD camera (Gatan, CA, USA).

Western blot. Protein lysates were prepared according to Mahon et al. ${ }^{41}$ Protein concentration was measured by the BCA Protein Assay (Pierce, Rockford, IL, USA) and the lysates were stored at $-80^{\circ} \mathrm{C}$. Equal amounts of protein were separated by electrophoresis on an SDS-PAGE 12.5 or $15 \%$ and transferred to a PVDF membrane as described ${ }^{42}$ (Biorad, Marnes-La-Coquette, France). After blocking, the membrane is incubated with primary antibodies and secondary antibodies. Protein-antibody complexes were detected by an enhanced chemiluminescence immunoblotting ECL (Perkin Elmer, Courtaboeuf, France).

Flow cytometry. Cells ( $10^{5}$ cells) were incubated for $15 \mathrm{~min}$ in $500 \mu$ l of PBS with $2 \mathrm{mM} \mathrm{Ca}{ }^{2+}, 2 \mu$ of Annexin-V-FITC (or APC) and $0.25 \mu \mathrm{g}$ of PI before flow cytometry analysis on Facscalibur. Ten thousand events are acquired for statistical analysis. Detection of autophagy was performed according to the manufacturer instructions (Enzo life sciences). Briefly, K562 cells $\left(5 \times 10^{4}\right)$ were incubated with dual-detection solution for $30 \mathrm{~min}$ in the dark and then diluted with PBS before flow cytometry analysis. 
SA- $\beta$-galactosidase labeling. Sa- $\beta$-galactosidase was detected according to Dimri et al. ${ }^{43}$ Briefly, cells ( $10^{5}$ cells) were fixed for $15 \mathrm{~min}$ with $3 \%$ PFA, then washed once with PBS. Cells were then incubated in a 96-well plate with a mix (1vol/20vol) of solution I containing X-Gal $(20 \mathrm{mg} / \mathrm{ml} \mathrm{X-Gal} \mathrm{in} \mathrm{dimethylformalde-}$ hyde) and solution II (5 mM ferricyanure, $5 \mathrm{mM}$ ferrocyanure, $2 \mathrm{mM} \mathrm{MgCl}_{2} 150 \mathrm{mM}$ $\mathrm{NaCl}, 30 \mathrm{mM}$ Citric acid/phosphate $\mathrm{pH}=6$ ) for $24 \mathrm{~h}$ at $37^{\circ} \mathrm{C}$. Cells were then washed with PBS and SA- $\beta$-gal activity was observed by detection of cells with a blue staining using an inverted Nikon Microscope (Eclipse Ti) and analyzed with the Nikon software NIS (Nikon France Instruments, Champigny, France). For SA- $\beta$-gal-positive staining cell quantification, 100 cells were counted on three separate fields and the mean of blue-stained cells was calculated as followed (number of blue cells/(number of total cells)). Results are expressed as percent of SA- $\beta$-gal-positive cells.

Apoptosis inhibition by Bim shRNA silencing or Bcl2 overexpression. To inhibit apoptosis, HIV-1 lentivirus-based vectors were used to introduce shRNAs against Bim or the complementary DNA of Bcl2 into cells as previously described. ${ }^{44}$ Briefly, shRNAs were cloned in FG12 lentivector, HEK293FT cells were used as packaging cells for virus production. To confirm silencing of Bim or overexpression of Bcl2, infected cells were sorted using GFPpositive cell detection and specific protein expression was detected by western blot.

Autophagy inhibition by RNA silencing. To inhibit autophagy, HIV-1 lentivirus-based vectors were used to introduce shRNAs against ATG7 or Beclin-1 as already reported. ${ }^{38}$ Briefly, shRNAs were cloned in FG12 lentivector, HEK293FT cells were used as packaging cells, and virus production was performed as previously described. ${ }^{24,38}$ ShRNA anti-ATG5 were purchased from ABgene (Courtabeuf, France) and five different sequences were tested for ATG5 inhibition (target set, pLKO.1). To confirm autophagy inhibition by silencing of ATG7, and Beclin-1, cells were grown in nutrient-deprivated medium (HBSS) in the absence or in the presence of Bafilomycin A, and both LC3B I and II form were detected by western blot. For ATG5-deficient cells, the inhibition of autophagy was confirmed using the Cyto-ID autophagy detection kit in comparison to K562 cells.

Statistical analysis. A Wilcoxon test was used to calculate differences between means; differences were considered significant only when $P \leq 0.05$ and shown by an asterisk.

\section{Conflict of Interest}

The authors declare no conflict of interest.

Acknowledgements. We thank Dr. Elisabeth Buchdunger and Paul Manley (Novartis Pharma, Basel, Switzerland) for providing us imatinib. This work was supported by la Ligue Nationale Contre le Cancer Comité de la Dordogne, l'Université Bordeaux Ségalen, la région Aquitaine and l'INSERM. CD is supported by la Ligue Nationale Contre le Cancer.

1. Melo JV. The molecular biology of chronic myeloid leukaemia. Leukemia 1996; 10: 751-756.

2. Druker BJ, Tamura S, Buchdunger E, Ohno S, Segal GM, Fanning $S$ et al. Effects of a selective inhibitor of the Abl tyrosine kinase on the growth of Bcr-Abl positive cells. Nat Med 1996; 2: 561-566.

3. Buchdunger E, Cioffi CL, Law N, Stover D, Ohno-Jones S, Druker BJ et al. Abl proteintyrosine kinase inhibitor STI571 inhibits in vitro signal transduction mediated by c-kit and platelet-derived growth factor receptors. J Pharmacol Exp Ther 2000; 295: 139-145.

4. Ertmer A, Huber V, Gilch S, Yoshimori T, Erfle V, Duyster J et al. The anticancer drug imatinib induces cellular autophagy. Leukemia 2007; 21: 936-942.

5. Puissant A, Colosetti P, Robert G, Cassuto JP, Raynaud S, Auberger P. Cathepsin B release after imatinib-mediated lysosomal membrane permeabilization triggers BCR-ABL cleavage and elimination of chronic myelogenous leukemia cells. Leukemia 2010; 24: 115-124.

6. Okada M, Adachi S, Imai T, Watanabe K, Toyokuni SY, Ueno M et al. A novel mechanism for imatinib mesylate-induced cell death of BCR-ABL-positive human leukemic cells: caspase-independent, necrosis-like programmed cell death mediated by serine protease activity. Blood 2004; 103: 2299-2307.
7. Lavallard VJ, Pradelli LA, Paul A, Beneteau M, Jacquel A, Auberger P et al. Modulation of caspase-independent cell death leads to resensitization of imatinib mesylate-resistant cells. Cancer Res 2009; 69: 3013-3020.

8. Golstein P, Kroemer G. Cell death by necrosis: towards a molecular definition. Trends Biochem Sci 2007; 32: 37-43.

9. Scarlatti F, Granata R, Meijer AJ, Codogno P. Does autophagy have a license to kill mammalian cells? Cell Death Differ 2009; 16: 12-20.

10. Codogno P, Meijer AJ. Autophagy and signaling: their role in cell survival and cell death. Cell Death Differ 2005; 12(Suppl 2): 1509-1518.

11. Klionsky DJ, Abeliovich H, Agostinis P, Agrawal DK, Aliev G, Askew DS et al. Guidelines for the use and interpretation of assays for monitoring autophagy in higher eukaryotes. Autophagy 2008; 4: 151-175.

12. Levine B, Yuan J. Autophagy in cell death: an innocent convict? J Clin Invest 2005; 115: 2679-2688.

13. Puissant A, Robert G, Fenouille N, Luciano F, Cassuto J-P, Raynaud $S$ et al. Resveratrol promotes autophagic cell death in chronic myelogenous leukemia cells via JNK-mediated p62/SQSTM1 expression and AMPK activation. Cancer Res 2010; 70: 1042-1052.

14. Eisenberg-Lerner A, Bialik S, Simon H-U, Kimchi A. Life and death partners: apoptosis, autophagy and the cross-talk between them. Cell Death Differ 2009; 16: 966-975.

15. Narita M, Young AR. Autophagy facilitates oncogene-induced senescence. Autophagy 2009; 5: 1046-1047.

16. Hayflick L. The limited in vitro lifetime of human diploid cell strains. Exp Cell Res 1965; 37 : 614-636.

17. Braig M, Schmitt CA. Oncogene-induced senescence: putting the brakes on tumor development. Cancer Res 2006; 66: 2881-2884.

18. Schmitt CA, Fridman JS, Yang M, Lee S, Baranov E, Hoffman RM et al. A senescence program controlled by $\mathrm{p} 53$ and p16INK4a contributes to the outcome of cancer therapy. Cell 2002; 109: 335-346.

19. Caino MC, Meshki J, Kazanietz MG. Hallmarks for senescence in carcinogenesis: novel signaling players. Apoptosis 2009; 14: 392-408.

20. Shay JW, Roninson IB. Hallmarks of senescence in carcinogenesis and cancer therapy. Oncogene 2004; 23: 2919-2933.

21. Ohtani N, Mann DJ, Hara E. Cellular senescence: Its role in tumor suppression and aging. Cancer Sci 2009; 100: 792-797.

22. Liu Y, Perdreau SA, Chatterjee P, Wang L, Kuan SF, Duensing A. Imatinib mesylate induces quiescence in gastrointestinal stromal tumor cells through the CDH1-SKP2p27Kip1 signaling axis. Cancer Res 2008; 68: 9015-9023.

23. Podtcheko A, Ohtsuru A, Namba H, Saenko V, Starenki D, Palona I et al. Inhibition of ABL tyrosine kinase potentiates radiation-induced terminal growth arrest in anaplastic thyroid cancer cells. Radiat Res 2006; 165: 35-42.

24. Drullion C, Lagarde V, Gioia R, Legembre P, Priault M, Cardinaud B et al. Mycophenolic acid overcomes imatinib and nilotinib resistance of chronic myeloid leukemia cells by apoptosis or a senescent-like cell cycle arrest. Leuk Res Treat 2011; 2012 $1-9$.

25. Druker BJ. Effects of a selective inhibitor of the Abl tyrosine kinase on the growth of Bcr-Abl positive cells. Nat Med 1996; 2: 561-566.

26. Belloc F, Moreau-Gaudry F, Uhalde M, Cazalis L, Jeanneteau M, Lacombe F et al. Imatinib and nilotinib induce apoptosis of chronic myeloid leukemia cells through a Bim-dependant pathway modulated by cytokines. Cancer Biol Ther 2007; 6: 912-919.

27. Rebbaa A, Zheng X, Chou PM, Mirkin BL. Caspase inhibition switches doxorubicin-induced apoptosis to senescence. Oncogene 2003; 22: 2805-2811.

28. Demarchi F, Cataldo F, Bertoli C, Schneider C. DNA damage response links calpain to cellular senescence. Cell Cycle 2010; 9: 755-760.

29. Wilhelm E, Fo-X Pellay, Benecke A, Bell B. TAF6Î controls apoptosis and gene expression in the absence of p53. PLOS ONE 2008; 3: e2721.

30. Dix MM, Simon GM, Cravatt BF. Global mapping of the topography and magnitude of proteolytic events in apoptosis. Cell 2008; 134: 679-691.

31. Young AR, Narita M. Connecting autophagy to senescence in pathophysiology. Curr Opin Cell Biol 2010; 22: 234-240.

32. Young AR, Narita M, Ferreira M, Kirschner K, Sadaie M, Darot JF et al. Autophagy mediates the mitotic senescence transition. Genes Dev 2009; 23: 798-803.

33. White E, Lowe SW. Eating to exit: autophagy-enabled senescence revealed. Genes Dev 2009; 23: 784-787.

34. Demidenko ZN, Zubova SG, Bukreeva El, Pospelov VA, Pospelova TV, Blagosklonny MV. Rapamycin decelerates cellular senescence. Cell Cycle 2009; 8: 1888-1895.

35. Kang HT, Lee KB, Kim SY, Choi HR, Park SC. Autophagy impairment induces premature senescence in primary human fibroblasts. PLOS ONE 2011; 6: e23367.

36. Luo Y, Zou P, Zou J, Wang J, Zhou D, Liu L. Autophagy regulates ROS-induced cellular senescence via p21 in a p38 MAPKÎ \pm dependent manner. Exp Gerontol 2011; 46: 860-867.

37. Chang NC, Nguyen M, Germain M, Shore GC. Antagonism of Beclin 1-dependent autophagy by BCL-2 at the endoplasmic reticulum requires NAF-1 2010EMBO J29: 606-618.

38. Priault M, Hue E, Marhuenda F, Pilet $P$, Oliver L, Vallette FM. Differential dependence on Beclin 1 for the regulation of pro-survival autophagy by Bcl-2 and Bcl-xL in HCT116 colorectal cancer cells. PLoS One 2010; 5 : e8755.

39. Sheng Z, Ma L, Sun JE, Zhu LJ, Green MR. BCR-ABL suppresses autophagy through ATF5-mediated regulation of mTOR transcription. Blood 2011; 118: 2840-2848. 
40. Puissan A, Dufies M, Raynaud S, Cassuto JP, Auberger P. Targeting lysosomes to eradicate imatinib-resistant chronic myelogenous leukemia cells. Leukemia 2010; 24: 1099-1101.

41. Mahon FX, Hayette S, Lagarde V, Belloc F, Turcq B, Nicolini F et al. Evidence that resistance to nilotinib may be due to BCR-ABL, Pgp, or Src kinase overexpression. Cance Res 2008; 68: 9809-9816.

42. Pocaly M, Lagarde V, Etienne G, Dupouy M, Lapaillerie D, Claverol S et al. Proteomic analysis of an imatinib-resistant K562 cell line highlights opposing roles of heat shock cognate 70 and heat shock 70 proteins in resistance. Proteomics 2008; 8: 2394-2406.

43. Dimri GP, Lee X, Basile G, Acosta M, Scott G, Roskelley C et al. A biomarker that identifies senescent human cells in culture and in aging skin in vivo. Proc Natl Acad Sci USA 1995; 92: 9363-9367.
44. Gioia R, Leroy C, Drullion C, Lagarde V, Etienne G, Dulucq S et al. Quantitative phosphoproteomics revealed interplay between Syk and Lyn in the resistance to nilotinib in chronic myeloid leukemia cells. Blood 2011; 118: 2211-2221.

Cell Death and Disease is an open-access journal published by Nature Publishing Group. This work is licensed under the Creative Commons Attribution-NonCommercial-No Derivative Works 3.0 Unported License. To view a copy of this license, visit http://creativecommons.org/licenses/by-nc-nd/3.0/

Supplementary Information accompanies the paper on Cell Death and Disease website (http://www.nature.com/cddis) 